\title{
1. Software and graphical user interfaces
}

\author{
Noam Shemtov
}

\section{INTRODUCTION}

But for the breakthrough innovators of the 21 st century, design has moved onto a much larger stage. It is where high function meets high style. And the traditional disciplines of IP - patents, trademarks and copyrights - are no longer ends unto themselves but are now viewed as component parts of a larger whole. This 'design in the large' is driving new business strategies and success as never before, as leading-edge companies harness the power of converging IP disciplines to deliver brands, inventions and content that differentiate not just their products in the market, but the companies themselves. ${ }^{1}$

In the above quotation David Kappos refers to the significance of designs and, in particular, 'designs in the large' to the overall success of products and services. Copyright, patent, trademark and industrial design laws are used in conjunction to provide a multilayered tapestry of protection to products' get-up or trade dress. In the case of software-based products or services, legal protection of graphical user interfaces (GUIs) is of particular significance.

During the past decade or so, software-based devices developed significant capabilities to process, manipulate, store and present data. Obviously, such capabilities would be of little benefit if users could not access and make use of them with ease. Market players in this area invest considerable resources in developing GUIs that enable users to do just that and, in so doing, render their device, their software or their service more appealing to consumers. Manufacturers often use the same GUI across a variety of devices - a 'house style' - so that consumers became accustomed to its 'look and feel' and develop loyalty to that particular brand. The substantial investment made in developing GUIs is primarily protected through intellectual property laws.

However, the implications of protecting GUIs under intellectual property laws are potentially far reaching. Take for example, the following advertisement from Corel: 'With a familiar Ribbon-style interface, Corel ${ }^{\circledR}$ Office looks like the office software you're used to, making it easy to get to work right away.' ${ }^{3}$ What is the most likely reason for Corel's reproduction of Microsoft's working environment? Is it its wish to appropriate the technical ingenuity

1 David Kappos, 'The New Frontier of Intellectual Property' (The National Law Journal, 22 April 2013) < www.cravath.com/files/Uploads/Documents/Publications/3407702_1.pdf > accessed 23 October 2019. Mr Kappos was Under Secretary of Commerce for Intellectual Property and Director of the United States Patent and Trademark Office (USPTO) from 2009 to 2013, and was Vice President for Intellectual Property for IBM.

2 For example, see Apple's GUI in its iPhone, iPod and iPad products.

3 Part of Corel's advertising, as referred to in Microsoft's claim against Corel, filed in the Northern District Court of California on 28/12/2015; see $<$ https://regmedia.co.uk/2015/12/30/msft_v_corel.pdf $>$ accessed 23 October 2019. On 13 February 2018 a jury verdict was delivered in favour of Microsoft, finding infringement by Corel in relation to two utility patents and four design patents: see Case 5:15-cv-05836-EJD Document 319 Filed 02/13/18, at <www.ipwatchdog.com/wpcontent/uploads/2018/ 02/05836-jury-verdict.pdf $>$. 
embedded in this working environment? Is it about appropriating its aesthetics as it enhances the product's appeal? Or is it about Microsoft Office's GUI as an indication of origin with which Corel wishes to affiliate itself? It might very well be that the answer to all of these questions is, to an extent, affirmative. However, most likely the main reason for reproducing the Microsoft Office working environment is Microsoft's existing customer base, who might be 'locked' into that particular product, in that they are now accustomed to its particular method of operation and behaviour and are not likely to switch to another working environment easily, even if the latter is objectively preferable. In this context, it is useful to recall Judge Boudin's concurring opinion in Lotus Dev. Corp. v Borland Int'l, Inc. ${ }^{4}$ The case concerned copyright infringement in a menu command hierarchy, an element of a GUI. It addressed, inter alia, the phenomenon of consumers' 'lock in' in relation to user interfaces and the 'cost' involved in protecting a method of operation under copyright law. The problematic repercussions of protecting user interface components under the circumstances were well captured in Judge Boudin's opinion, where he observed:

But if a better spreadsheet comes along, it is hard to see why customers who have learned the Lotus menu and devised macros for it should remain captives of Lotus because of an investment in learning made by the users and not by Lotus. Lotus has already reaped a substantial reward for being first; assuming that the Borland program is now better, good reasons exist for freeing it to attract old Lotus customers: to enable the old customers to take advantage of a new advance, and to reward Borland in turn for making a better product. If Borland has not made a better product, then customers will remain with Lotus anyway. ${ }^{5}$

It is often the case that notwithstanding the underlying code, a major element of the commercial value of a piece of software rests with its user interface and how it appeals to software users. Issues such as the GUI's eye appeal, how intuitive it is to use and its 'user-friendliness' will be crucial to the success of a given software-driven product or service. Where that is the case, attempts to replicate such GUI aspects are to be expected. The extent to which intellectual property laws in the EU may regulate such attempts is the focus of this chapter.

The term GUI has been described by the Court of Justice of the European Union (CJEU) as an 'interaction interface which enables communication between the computer program and the user'. ${ }^{6}$ The term GUI will be used here in a broad sense to include both textual and graphical elements of users' screen displays. This chapter will focus its discussion on three categories of GUI elements: (1) the desktop - referring to the entire display area; (2) static components - the items appearing on the display area, such as pointers, icons and menus; and (3) animated effects or motion features, such as the gene effect on the Mac operating system. Additionally, this chapter will address the impact made by GUIs on the user in a broader sense, referring to the 'look and feel' of software which is generated by these three GUI categories.

The analysis below is conducted under four distinct branches of intellectual property law: copyright, patents, design law and trade dress protection (to the extent that such protection is

(1st Cir. 1995) 49 F.3d 807, 815.

ibid para 78.

6 Case C-393/09 Bezpečnostní Softwarová Asociace - Svaz Softwarové Ochrany v Ministerstvo Kultury [2011] FSR 18 ('BSA') para 40. 


\section{Research handbook on intellectual property and digital technologies}

available under trade mark law). When examining the protectability of GUIs under EU law, ${ }^{7}$ it should be borne in mind that often GUIs are both aesthetic and functional. As we shall see, this duality poses specific challenges to the intellectual property law framework.

\section{THE PROTECTABILITY OF GUIS UNDER COPYRIGHT LAW}

While it is hardly arguable these days that software's underlying code, including the part responsible for the GUI, is protectable under copyright law, the protectability of software's visual aspects under copyright law is somewhat more contentious. Moreover, copyright eligibility for software's overall 'look and feel', often generated by the GUI, which in turn constitutes its user experience, is not straightforward. As we shall see, such assessment is highly fact sensitive and must factor in considerations that may vary extensively between one set of factual circumstances and another.

\subsection{Background Statutory Framework}

At first glance the statutory framework that governs copyright protectability of various aspects of computer programs is clearly identifiable as the Software Directive. ${ }^{8}$ Thus, Recital 7 of the Software Directive provides:

For the purpose of this Directive, the term 'computer program' shall include programs in any form, including those which are incorporated into hardware. This term also includes preparatory design work leading to the development of a computer program provided that the nature of the preparatory work is such that a computer program can result from it at a later stage.

However, in $B S A,{ }^{9}$ the CJEU concluded that the protectability of GUIs in their non-code form is not governed by the Software Directive but rather by the Information Society Directive. ${ }^{10} \mathrm{Of}$ particular relevance to the present context was the first question referred by the regional Court of Prague, which essentially enquired whether Article 1 of the Software Directive should be 'interpreted as meaning that, for the purposes of the copyright protection of a computer program as a work under that directive, the phrase "the expression in any form of a computer program" also includes the graphic user interface of the computer programme or part thereof?'11

The CJEU's reply was negative. It maintained that the objective of the Software Directive is to afford 'expression in any form of a computer program which permits reproduction in different computer languages, such as the source code and the object code'. ${ }^{12}$ This being

\footnotetext{
7 In the case of patent law, I refer to the European Patent Convention 1973 (EPC) and the jurisprudence developed by the European Patent Office (EPO); this legal framework is applicable throughout the EU.

8 Directive 2009/24/EC of the European Parliament and of the Council of 23 April 2009 on the legal protection of computer programs.

9 Bezpečnostní (n 6).

10 Directive 2001/29/EC of the European Parliament and of the Council of 22 May 2001 on the harmonisation of certain aspects of copyright and related rights in the information society.

11 Bezpečnostní (n 6) para 21.

12 Bezpečnostní (n 6) para 35.
} 
so, it followed that as 'the [GUI] does not enable the reproduction of the computer program itself, but merely constitutes one element of that program by means of which users make use of the features of that program', ${ }^{13}$ it did not constitute a 'computer program' within the meaning of the Software Directive. This, of course, does not mean that GUIs or parts thereof are not eligible for copyright protection per se, but merely provides that such protection is not afforded under the Software Directive. Hence, the CJEU explained that just like any other authorial work, a GUI or components thereof might qualify as a protectable subject matter under the Information Society Directive. It stressed, however, that 'where the expression of those components is dictated by their technical function, the criterion of originality is not met, since the different methods of implementing an idea are so limited that the idea and the expression become indissociable'. ${ }^{14}$ Hence, the court stipulated that when assessing copyright eligibility of GUIs or components thereof, one should examine whether the form in which such components are expressed is dictated by functional considerations. Where this is the case, the GUI at issue, or components thereof, will be considered as not meeting the originality criterion and thus not eligible for copyright protection. This raises the question: When is a component 'dictated' by functional considerations? Is it about the motivation behind a given design choice? Is about the number of available alternatives? It appears that the CJEU favours the latter interpretation, essentially referring to a merger-like consideration according to which there are either no available alternatives or the number of such alternatives is highly limited.

The $B S A$ ruling should not be taken as implying that the Software Directive has no role to play in determining protectability of GUIs or elements thereof under copyright law. In this context, Recital 20 of the Information Society Directive should be borne in mind. It states:

This Directive is based on principles and rules already laid down in the Directives currently in force in this area, in particular [Directive 91/250], and it develops those principles and rules and places them in the context of the information society. The provisions of this Directive should be without prejudice to the provisions of those Directives, unless otherwise provided in this Directive.

It follows that when interpreting and applying the provisions of the Information Society Directive, it might be necessary to use as an interpretative tool the rules and principles established under the Software Directive.

\subsection{Eligibility}

The starting point for establishing the criteria for copyright protection under the Information Society Directive is the CJEU decision in Infopaq. ${ }^{15}$ Notwithstanding the fact that the Directive does not explicitly stipulate a general eligibility criterion, and in particular does not seek to define a unified originality threshold, the CJEU found that such a threshold could in fact be discerned by reading the Directive rather broadly; hence, a harmonised EU originality threshold was identified as the 'author's own intellectual creation'. The court arrived at this conclusion by drawing support from the fact that this threshold has been explicitly stipulated in

13 Bezpečnostní (n 6) para 41.

14 Bezpečnostní (n 6) para 49.

15 Case C-5/08 Infopaq International A/S v Danske Dagblades Forening [2010] FSR 20. 
other Directives, such as the Software Directive and the Database Directive, ${ }^{16}$ on the principles of which the Information Society Directive was based. According to the court, this effectively means that the same originality standard should be applied across the board, whether or not the subject matter at issue relates to computer programs or databases, including in instances where the copyright-eligible subject matter is governed by the Information Society Directive. ${ }^{17}$ A significant part of the criticism levelled against the creation of a unified originality criterion without any explicit basis in the Information Society Directive originated from the UK, which had traditionally adhered to the 'skill, labour and judgement' test for evaluating originality. Infopaq implied, and indeed the Opinion of the Advocate General in Football Dataco confirmed, that the skill, labour and judgement criterion constituted a lower, more easily met, threshold in comparison with the EU threshold of 'author's own intellectual creation' ${ }^{18}$

Consequently, the present legal position provides that (1) the protectability of GUIs as a copyright work is governed by the Information Society Directive; (2) the originality threshold under the said Directive means the author's own intellectual creation; and (3) GUI elements dictated by their technical function are not 'original' within the meaning of the Information Society Directive. While the exclusion of elements dictated by technical function may appear to be clear, this requires further elaboration.

The CJEU referred to the nature of this harmonised originality test in several rulings, each dealing with a different subject matter, varying from football matches to photographs to databases. Hence, in Painer the court stated that: 'an intellectual creation is an author's own if it reflects the author's personality' ${ }^{19}$ It explained: ' $[\mathrm{t}]$ hat is the case if the author was able to express his creative abilities in the production of the work by making free and creative choices. ${ }^{20}$ It is by making these choices that the author stamps the created work with his 'personal touch' ${ }^{21}$ The same reference to the author's 'personal touch' by virtue of his free and creative choices was made in Football Dataco: 'that criterion of originality is satisfied when, through the selection or arrangement of the data which it contains, its author expresses his creative ability in an original manner by making free and creative choices.' ${ }^{22}$ The CJEU stressed: '[b]y contrast, that criterion is not satisfied when the setting up of the database is dictated by technical considerations, rules or constraints which leave no room for creative freedom' (emphasis added). ${ }^{23}$ The same test was also used by the court in a case relating to software, where the particular subject matter was, like GUIs, thought to be protectable under the Information

\footnotetext{
16 Directive 96/9/EC of the European Parliament and of the Council of 11 March 1996 on the legal protection of databases.

17 The CJEU decision in Infopaq was heavily criticised, inter alia, on the grounds that the court effectively engaged in lawmaking rather than simply interpreting the Directive: see, for example, L. Bently 'Harmonisation by Stealth: Copyright and the ECJ' Presentation at 20th Annual Intellectual Property Law \& Policy Conference (April 2012) available at <http://fordhamipconference.com/wp-content/ uploads/2010/08/Bently_Harmonization.pdf $>$ accessed 23 October 2019; S. Vousden, 'Infopaq and the Europeanisation of Copyright Law' (2010) 1 WIPOJ 197; E. Rosati, 'Originality in a Work, or a Work of Originality: The Effects of the Infopaq Decision' [2011] 33 EIPR 746.

18 See Case C-604/10 Football Dataco Ltd, and others $v$ Yahoo! UK Ltd and others [2012] 2 CMLR 24, Opinion of AG Mengozzi, para AG37.

19 C-145/10 Eva-Maria Painer v Standard Verlags GmbH [2011] ECDR 297, para 88.

20 ibid para 89.

21 ibid para 92.

22 Football Dataco (n 18) para 38.

23 Football Dataco (n 18) para 39.
} 
Society Directive rather than the Software Directive. Hence, on the issue of whether and to what extent items such as keywords, syntax and commands constituted 'intellectual creation', the CJEU in SAS maintained that '[i]t is only through the choice, sequence and combination of those words, figures or mathematical concepts that the author may express his creativity in an original manner and achieve a result, namely the user manual for the computer program, which is an intellectual creation'. ${ }^{24}$ Finally, explicitly referring to originality in GUIs, the court in $B S A$ provided that 'the national court must take account, inter alia, of the specific arrangement or configuration of all the components which form part of the graphic user interface in order to determine which meet the criterion of originality. In that regard, that criterion cannot be met by components of the graphic user interface which are differentiated only by their technical function. ${ }^{25}$

Thus, according to the CJEU, the concept of 'the author's own intellectual creation' indicates the following: (1) a laborious, time and cost intensive, yet mechanical creation process will not suffice; (2) in order to be considered 'intellectual' rather than a mechanical creation, the authorial process should involve 'free and creative' choices; hence, not only must intellectual creation involve a degree of freedom of choice, but such free choices must also be creative. At first glance the requirement for 'creativity' appears to add little to the concept of freedom of choice. Could a choice that was not wholly dictated by external considerations, such as functionality, and in that sense 'free' not be considered as 'creative' within copyright law's context? After all, it is trite law that no qualitative filter should be used when assessing originality. If this is so, what is the difference between mere 'free choice' and both 'free and creative' choice? Some commentators appear to hold the view that 'to choose is not equivalent to create' ${ }^{26}$ In order to illustrate such difference, Waisman gives one Argentine judgment as an example, in which it was concluded that the expression 'jeans for men and women between two and twelve years old' could not be considered original. ${ }^{27}$ She contends that it is difficult to argue that this phrase does not result from its author's free choice, or that the author had no alternatives to convey the same message. It is suggested that the actual basis for the Argentine decision may have been the mundane and commonplace nature of the said phrase; in this sense it may be described as a noncreative choice by the author. In GUI context it adds very little, as it suggests that mundane and commonplace designs, whether for desktops, outlays or individual items, will not meet the required originality threshold.

The above discussion supports a number of inferences. First, and most importantly, the expressive nature of the GUI is not outweighed by its utilitarian objective. Hence, unlike the Court of Appeals for the First Circuit in Lotus, ${ }^{28}$ and similar to the Court of Appeal for the Federal Circuit in Oracle v Google ${ }^{29}$ the CJEU does not maintain that once a functional objective of a subject matter or part thereof has been clearly identified, the inquiry as to copyright eligibility should be terminated and the said item should be tagged as noncopyrightable under the idea-expression dichotomy. Rather, what should be determined is whether the manner in

Case C-406/10 SAS Institute v World Programming [2012] 3 CMLR 4, para 67.

Bezpečnostní (n 6) para 48.

26 See, for example, Alain Strowel, Droit d'Auteur et Copyright - Divergentes et convergentes. Etude de droit comparé (Bruylany Bruxelles LGDJ Paris 1993), 406.

27 Augustin Waisman, 'Revisiting Originality' [2009] EIPR 370, 375.

28 Lotus (n 4).

29 Oracle Am. Inc. v Google Inc. (2014) 750 F.3d 1339 (Fed. Cir.). 
which the said utilitarian item was expressed was dictated by functionality without there being a reasonable number of alternatives to express that item. Where there are such alternatives, copyright protection may be afforded, subject to a showing that the chosen form of expression resulted from the exercise of free and creative choices. In this context it should be borne in mind that even where functional constraints do not dictate the chosen form of expression and some free choice is exercised, the originality threshold nevertheless may not be met where such choices are commonplace.

Although the relevant passage in the $B S A$ decision focuses on selection and configuration of all the components of a GUI, ${ }^{30}$ it is submitted that the same rules should equally apply to individual GUI components. Hence, although it may be more burdensome to successfully establish that an individual component resulted from free and creative exercise of choice, it is perfectly possible to do so under suitable circumstances. This holds in relation to both static and animated GUI components. Not all instances where there is some freedom of choice in coming up with a certain GUI design automatically result in 'intellectual creation'; such free choice must also be 'creative', as in originating from the author rather than being commonplace. In this context, it must be borne in mind that a 'creative' element in a decision to make a certain GUI function available in a particular instance of user-software interaction is not taken into account when assessing originality; rather, it is more likely to reside on the 'idea' side of the idea-expression divide. It is only the 'creative' element that goes into the decision to express such a function in a particular way in a GUI that could render the component representing this function copyright-eligible. Hence, a certain artwork representing an icon may be considered as copyright-eligible due to the fact that its configuration and design was neither dictated by functional considerations nor commonplace or mundane. The same principle would apply to pointers, although for obvious reasons it is less likely that many would successfully meet this requirement. When considering menus, an approach similar to that taken in relation to compilations could be followed; namely, whether the selection and arrangement of items in the said menu reflects the author's free and creative choices. As mentioned, the fact that an item is designed primarily in order to achieve a functional utilitarian objective should not render it non-eligible to copyright protection.

Finally, when referring to the overall 'look and feel' of a GUI, it may be useful to break this down into its constituent parts: (1) look and (2) feel. ${ }^{31}$ The discussion above mainly relates to the various aspects of the 'look' element. Turning to the 'feel' factor, its eligibility for copyright protection may be more contentious. Speaking of the 'feel' factor of a GUI usually relates to the interactions enabled by such GUI, for example, the manner in which functions are selected and performed. Such issues are essentially one facet of a larger software functionality debate. This debate is discussed in detail in Chapter 2.

\subsection{Scope of Protection}

Once it has been established that a given GUI or components thereof are eligible for copyright protection, the next question might be: under which circumstances may copyright infringement in relation to the said GUI take place?

\footnotetext{
30 Bezpečnostní (n 6) para 48.

31 In juridical contexts, this term originates from US jurisprudence; to the best of this author's knowledge, it has not yet been employed by the CJEU.
} 
The decision of the CJEU in Infopaq suggests that, in essence, the infringement question under the Information Society Directive is conceptually related to the eligibility assessment. The court stated:

the reproduction of an extract of a protected work which, like those at issue in the main proceedings ... is such as to constitute reproduction in part within the meaning of Article 2 of Directive 2001/29, if that extract contains an element of the work which, as such, expresses the author's own intellectual creation; it is for the national court to make this determination. ${ }^{32}$

Therefore, when determining whether the part taken is sufficient to constitute copyright infringement, the court must assess whether such part reflects the author's own intellectual creation. In order to do so, the court must evaluate whether the part taken meets the eligibility criteria discussed above.

Unlike the position under US law, where prima facie infringement may still be excused under the fair use defence, EU copyright law does not provide for a similar overarching judicial mechanism. In the GUI context, which is primarily intended to enable interaction between software and its users, Judge Boudin's statement should be borne in mind. In Lotus the court held the menu command hierarchy at issue ineligible for copyright protection on the basis of its functional nature. This approach was heavily criticised by the Court of Appeals for the Federal Circuit in Oracle $v$ Google, which contended that the functional nature of the subject matter at issue should not per se impact its eligibility for copyright protection; rather, courts should focus on the manner in which the author chooses to express such subject matter. Where the chosen form of expression was not dictated by functionality, the court should find in favour of copyright eligibility, notwithstanding any functional objective. The court in Oracle therefore overturned the lower court's decision and found Oracle APIs to be eligible for copyright protection. The court, however, stressed that Google's argument regarding commercial interoperability, although irrelevant for the eligibility inquiry, was clearly relevant for any fair use inquiry. ${ }^{33}$ In fact, on 26 May 2016 a jury found in favour of Google on that basis. This decision, however, was overturned on its facts by the Court of Appeals for the Federal Circuit on 27 March 2018. The court reversed the jury's verdict and found that Google's use of Java's APIs in order to create the Android operating system was not fair use. The court was not convinced by Google's argument regarding commercial interoperability in this context. ${ }^{34}$

Whether one favours the approach taken in Lotus or the one in Oracle v Google, it is suggested that neither approach may be open to an EU member state court when confronted with a scenario similar to the one described by Judge Boudin in Lotus. As mentioned earlier, the CJEU appears to have opted against the Lotus approach by focusing on the free and creative choices available to the author at the point of creation, rather than on the nature of the subject

\footnotetext{
$32 \quad$ Infopaq (n 15) para 48.
}

33 The court stated: 'while we have concluded that it was error for the trial court to focus unduly on the functional aspects of the packages, and on Google's competitive desire to achieve commercial "interoperability" when deciding whether Oracle's API packages are entitled to copyright protection, we expressly noted that these factors may be relevant to a fair use analysis' (Oracle (n 29) 1364).

34 When it implemented its Android operating system Google wrote its own Java. However, in order to enable developers that are accustomed to Java to write their programs for the Android operating system, Google used the same names, organization and functionalities of Java APIs. Therefore, one of the questions in this case was whether the need to have commercial interoperability between Google and the Java developers community weighed in favour of fair use. 
matter. But the approach endorsed by the Oracle v Google court is not open to an EU court simply because the Information Society Directive does not contain anything that remotely resembles the US fair use defence. ${ }^{35}$ Hence, pro-interoperability arguments similar to those made by Google have no place within the present EU copyright framework. If at all, such concerns may potentially be accommodated by EU competition law in a case of refusal to licence. ${ }^{36}$

\subsection{Summation}

In conclusion, it appears that GUIs or components thereof are eligible for copyright protection as long as they result from the exercise of free and creative choices made by the author. Essentially, this means that such choices should not be mundane or commonplace, and should not be dictated by technical function in the sense of having either no alternative designs or a very limited number of designs capable of performing the sought after function. It is suggested that in the majority of cases involving GUI designs, choices made in expressing such designs are not likely to be considered as dictated by technical function stricto sensu. In this context it should be stressed that the fact that a GUI or component thereof is designed to serve a functional objective of itself is of little consequence. Moreover, the fact that it is designed to serve a technical objective does not compromise its scope of protection, and the need to replicate such GUI or component thereof in order to make a certain software-based product or service more accessible to its potential user community in a manner similar to Lotus cannot be accommodated favourably under the EU's copyright regime. ${ }^{37}$

The position under EU law is somewhat unsatisfactory. It is submitted that the technical function of a given subject matter should play a role in determining its protectability under copyright law, even where such function did not dictate the form in which the said subject matter was originally expressed. Thus, even if a GUI designer had multiple choices at the point of time of designing a GUI, it may nevertheless be the case that due to the popularity of the said GUI, which was obviously gained after it was created, it had become functional in the sense of the user community's familiarity with it and their likely reluctance to migrate to a competing, different looking GUI design. Where this is so, there might be convincing reasons for allowing a competitor to emulate the key elements of the appearance of such GUI in order to enter the market and offer viable alternatives. Referring the competitor in such instances to competition law misses the point; it is the public policy considerations that stand at the heart of copyright law that may justify suspension of our general rules on protectability in the case of a design that is judged to be functional at the point of time in which the alleged infringement takes place.

35 Notwithstanding the fact that in reversing the Jury's verdict, the court of appeal in Oracle concluded that Google's use did not amount to fair use under the circumstances of the case.

36 The successful application of Article 102 of the Treaty on the Functioning of the European Union under such circumstances is likely to be in the rarest of cases, as was the case with the decision in Case T-201/04 Microsoft Corp v Commission [2007] 5 CMLR 11.

37 Lotus (n 4). 


\section{PATENTING ELEMENTS OF GRAPHICAL USER INTERFACES}

Patent eligibility of software-implemented inventions in general is discussed in detail in Chapter 13. The discussion below focuses on patent protection for GUIs.

\subsection{Legislative Framework}

\section{Article 52 of the European Patent Convention (EPC) defines what constitutes patentable subject matter under the convention. It reads:}

(1) European patents shall be granted for any inventions, in all fields of technology, provided that they are new, involve an inventive step and are susceptible of industrial application.

(2) The following in particular shall not be regarded as inventions within the meaning of paragraph 1:

(a) discoveries, scientific theories and mathematical methods;

(b) aesthetic creations;

(c) schemes, rules and methods for performing mental acts, playing games or doing business, and programs for computers;

(d) presentations of information.

(3) Paragraph 2 shall exclude the patentability of the subject-matter or activities referred to therein only to the extent to which a European patent application or European patent relates to such subject-matter or activities as such.

In essence, in order to obtain patent protection, the subject matter of the application must constitute an invention, involve novelty and inventive step and be capable of industrial application. ${ }^{38}$ While the requirements of industrial application and novelty must be complied with, they do not generally call upon special considerations in relation to GUI-related inventions and therefore will not be discussed in detail.

Articles 52(2) and (3) provide that a patent application that relates, inter alia, to schemes, rules and methods for performing mental acts, for playing games or doing business, for 'presentation of information' or a 'computer program' as such should be refused on the grounds of not being an 'invention' within the meaning of the EPC. Although in the past Article 52 used to be the main filter for excluding non-patentable subject matter in the case of computer implemented inventions at the EPO, this is no longer the case. In a series of decisions, the EPO gradually abandoned its earlier approach in favour of what is sometimes referred as the "whole content' approach or 'any hardware' approach. ${ }^{39}$ According to this approach, an application is not likely to fall foul of Article 52 as long as the claimed subject matter as a whole manifests a technical character. Such technical character will be manifested for the purpose of Article 52 whenever the subject matter is claimed in relation to a piece of hardware such as a computer rather than in abstract. This, however, does not mean that any computer-related application drafted in such a manner is likely to overcome the obstacle of the excluded areas identified in

38 Exceptions to patentability under Article 53 are of less relevance to the present discussion.

39 On case law development of the EPO in relation to computer implemented inventions see $\mathrm{N}$. Shemtov, 'The Characteristics of Technical Character and the Ongoing Saga in the EPO and the English Courts' (2009) 4 JIPLP 506; it is noteworthy that English courts still follow the earlier 'technical contribution' approach and filter out ineligible computer-related applications on the basis Article 52. 
Article 52. Thus, the excluded list under Article 52 still plays a vital role in evaluating computer implemented inventions, but the focus has now shifted to Article 56, which concerns the requirement of inventive step..$^{40}$ Hence, the excluded subject matter hurdle has essentially been moved from the eligibility enquiry stage to the patentability examination stage.

Only features that manifest technical character are taken into consideration when assessing an invention for novelty and inventive step. Thus, where the features distinguishing the invention at issue from the state of the art are considered non-technical and hence not taken into consideration, such invention is not likely to meet the requirements of Article 56, as it is likely to be obvious to the person skilled at the art. For example, where the distinguishing features are classified as being wholly within the field of 'presentation of information', they will be considered as nontechnical and therefore as being part of the state of the art for the purpose of assessing inventive step. Obviously, when what sets the invention apart from the state of the art, as a legal fiction, is considered part of the state of the art, and there is nothing 'technical' left in the application to differentiate the invention from the state of the art in a nonobvious manner, an inventive step assessment is likely to conclude that the invention at issue does not involve an inventive step.

\subsection{GUIs and Technical Character}

Ultimately, an inventive step assessment in the present context hinges on the determination of what does and does not constitute a technical effect or technical character. There is no clear general definition of what constitutes a technical effect, either in the EPC, in the Implementing Regulations, ${ }^{41}$ or in the jurisprudence of the Boards of Appeal. A good guide is a series of individual decisions of the Boards of Appeal where technicality was established; as previously mentioned, the list of exclusions under Article 52 may also be useful in this context.

The jurisprudence of the EPO on which aspects of GUI may or may not have a technical effect, and therefore not be automatically considered as part of the state of the art, is fairly mixed, although the direction of travel appears to be fairly consistent in the past few years; a stricter approach and a fairly narrow definition to the concept of technical effect are emerging as dominant in the EPO case law in relation to GUI. The Guidelines for Examination appear to define what constitutes the excluded 'Presentation of Information' category within the meaning of Article 52(2)(d), so that both the cognitive content and the manner in which the information is presented are likely to be considered as excluded aspects, while the technical means used to generate such presentation are not so excluded. ${ }^{42}$ However, the Guidelines may be oversimplifying the present legal position. It is submitted that although the manner in which the information is presented may not be considered as having a technical effect simply because it is claimed that it reduces the cognitive burden on the user, a technical effect may neverthe-

40 The list of noninventions under Article 52 may still play a role under the eligibility enquiry where the application as a whole does not manifest a technical character. However, as mentioned, the vast majority of cases involving computer implemented inventions manage to overcome this hurdle by drafting the application in manner involving technical hardware (cf. industrial application).

41 Implementing Regulations to the Convention on the Grant of European Patents of 5 October 1973, as adopted by decision of the Administrative Council of the European Patent Organisation of 7 December 2006 and as last amended by decision of the Administrative Council of the European Patent Organisation of 14 October 2015.

42 Guidelines for Examination, G-II, 3.7. 
less be constituted by establishing, for example, that the claimed manner of presentation has a certain objectively verified physiological effect on the user. This is so since while the former is essentially subjective and may vary from one user to another, the latter could in principle be objectively verified and hence fit better into the definition of technical character. The shift in the Boards of Appeal's view on what constitutes technical effect and technical character in the context of GUI may be demonstrated by a brief examination of a number of key decisions on this point.

\subsubsection{Technical effect in lowering cognitive burden - the previous position}

The decision of the Technical Board of Appeal in T333/95 serves as a starting point for examining the more lenient approach taken at the EPO towards the concept of technical effect in relation to GUIs. The application at stake concerned 'a method of creating an animation by moving a graphics object around a graphical display under control of a pointing device', where the graphic object was a cursor. This graphic object was found by the Board to have a technical character since it decreased 'both the necessary mental and physical effort of the operator, since the direct movement of the graphics object, obviously, does not need the concentration necessary when the operation must be performed by means of a normal cursor' ${ }^{43}$

The same relaxed approach towards the concept of technical effect was also applied in instances of applications directed to textual menus in GUIs. In T49/04 the Technical Board expressed an expansive view on what may constitute a technical character in GUI context. It stressed that 'a feature which relates to the manner how the "cognitive content", such as images, is conveyed to the user can very well be considered as contributing to a technical solution to a technical problem. This would in particular be the case when . . . this particular manner of conveying the information enables the user to perform their task more efficiently' ${ }^{44}$

In the same vein, the Technical Board in T928/03 concluded, inter alia, that a graphical marker in a user interface of a video football game, where the marker suggests the orientation of another prospective team player to which a player currently controlled by a user passes a ball, solved a problem that contributed to the technical function of the display. ${ }^{45}$

Following the above decisions, the EPO revised its Guidelines for Examiners, reflecting a lenient approach to technical effect. The 2012 Guidelines for Examiners suggested that although in most cases features relating to GUIs may not have a technical effect, this was not always the case. This was especially so where such features

are combined with interaction steps or means or when they concern technical information (e.g. internal machine states), the examiner must check whether they are necessary for achieving a particular technical effect, for example by enhancing the precision of an input device or by lowering the cognitive burden of a user when performing certain computer interactions. The technical effect achieved might be a more efficient man-machine interface. ${ }^{46}$ (Emphasis added)

Essentially, the Guidelines suggested that having a GUI that was more intuitive and user friendly, hence having the effect of 'lowering the cognitive burden' of the user, might be sufficient to constitute a technical effect.

43 Case T333/95 Interactive animation/I.B.M. ECLI:EP:BA:1997 Reasons 5.

44 Case T49/04 Text Processor/WALKER ECLI:EP:BA:2005 Reasons 4.6.3.

45 Case T 0928/03 Video game/KONAMI ECLI:EP:BA:2006.

46 Guideline G-II 3.7.1, in the 2012 Guidelines for Examination. 


\subsubsection{The present position - distinguishing between what and how information is presented}

The Boards of Appeal's change of heart regarding the EPO's readiness to consider 'lowering of cognitive burden' as constituting a technical effect could be traced to T1143/06, where it was stated that 'a feature which relates to the manner how cognitive content is conveyed to the user on a screen normally does not contribute to a technical solution to a technical problem. An exception would be if the manner of presentation can be shown to have a credible technical effect' ${ }^{47}$ Subsequently, the Technical Board in T1741/08 explicitly concluded that the lowering of the cognitive burden as a result of choices as to what or how to present information was not sufficient to generate a technical effect. ${ }^{48}$ The Guidelines were thereafter amended and the specific example of technical effect in the case of lowering the cognitive burden was removed. ${ }^{49}$ In addition, the new version of the Guidelines stipulated that the colour, size and shape of items on the screen do not usually amount to a technical aspect of a GUI.

Recently, in T1802/13, the Technical Board further elaborated on this issue and clarified that the aforementioned restrictive approach represents the present legal status quo. ${ }^{50}$ In this case the Board was faced with an appeal against a decision of the Examining Division to refuse an application, inter alia, on the grounds of lack of patentable subject matter as it concerned presentation of information as such. The application at issue related to a method of analysing brain tissue maps while engaging in disease analysis. In this decision the Technical Board was required to assess whether the feature by which 'a map is displayed in which the electrode leadwire and the predicted volume of activation are superimposed on the patient-specific atlas of the brain tissue ${ }^{51}$ constituted a presentation of information as such. The appellant argued that the said feature had the effect of lowering the cognitive burden of the user, which resulted in a more efficient man-machine interface, and that the objective problem to be solved by the said feature was the 'provision of an improved system that provides a more efficient method of selecting the electrode parameters for DBS' ${ }^{52}$ The Board rejected both contentions. It maintained that it was now the established jurisprudence of the Boards of Appeal that lowering the cognitive burden of a user per se could not in principle be considered as a technical effect. It also contended that it was mere speculation that the claimed feature credibly brought about the technical effect of accurately predicting the electrodes' properties and providing that information to the surgeon in an efficient manner. Rather, the Board concluded that the said feature merely amounted to presenting cognitive content that addressed solely the user's mental process. It thus appears that in order to conclude that a technical effect was involved, it was required to show a causal link between the presented brain tissue maps and the selection of electrode parameters for the deep brain stimulation procedure. However, the claimed feature in the application at stake merely assisted the user in selecting the relevant parameters, hence lowering the user's cognitive burden, but did not amount to an objective causal link between the map and the selected parameters. According to the Board, in order to establish the latter

\footnotetext{
See Reasons 5.4 of this decision. Case T 1741/08 GUI layout/SAP ECLI:EP:BA:2012.

Guideline G-II 3.7.1, in the 2013 Guidelines for Examination.

Case T1802/13 Brain stimulation/CLEVELAND ECLI:EP:BA:2016.

ibid Reasons 2.1.3.

ibid Reasons 2.1.6.
} 
and hence manifest technical effect, the information presented should be objectively provided by the claimed method, without being dependent on human discretion and skills.

\subsubsection{Summation}

In conclusion, features of GUIs may manifest the requisite technical character in exceptional cases only. For example, where the information provided in a GUI context credibly, causally and objectively assists the user, rather than merely contributing to the user's mental process. Also, where enhanced usability may be established by reference to, inter alia, objectively verifiable physiological considerations rather than mere claims of subjective intuitiveness, technical character may be acknowledged..$^{53}$

It is submitted that the present position leaves a lot to be desired. While is it acknowledged that 'reduction' of cognitive burden is not easy to establish as a psychological effect that takes place within the user's mind, it does not necessarily follow that where it is established in a convincing manner before the Board it should not be recognised as a qualifying technical effect. As mentioned elsewhere in this chapter, designing a GUI in a manner that makes it more intuitive in comparison to the state of the art enables the user to interact with the product or service at issue more efficiently, and as a result increases the usability of such product or service, which in turn could be central to commercial success. It is submitted that enhancing usability due to a successfully intuitive GUI design should in principle be open to patent protection. Hence, rather than entirely excluding from patentability such effect on a product's usability, it would have been preferable if the Boards could have come up with guidelines as to the manner in which one may objectively, as opposed to subjectively, demonstrate a reduction in the user's cognitive burden and the consequent improvement in the product's usability.

\section{PROTECTING GUIS UNDER EU TRADE MARK LAW}

In principle, all aspects of GUIs - the overall layout, individual static components and transitional or animated features - could be registered as trade marks under EU trade mark law. The elements of the GUI in respect of which protection is sought should be depicted in the application, and a broken line border may be used to represent a display screen (or portion thereof). There are, however, three absolute grounds for refusal that should be borne in mind in particular in this context, as they may pose a challenge to a party seeking to register GUIs or features thereof as a trade mark; these are discussed below. Once registered, such trade marks could be enforced in respect of infringing uses, as well as being used as a basis for opposition to applications for registration of conflicting marks under the general rules governing scope of protection and relative ground for refusal. Hence, the discussion below will focus on absolute ground for refusal, rather than on relative grounds for refusal or infringement.

\subsection{Devoid of Any Distinctive Character}

The EU IPO Boards of Appeal case law appears to suggest that the main obstacle to registering elements of GUIs as a trade mark is the requirement that a trade mark should not be devoid

53 Case T1375/11 SPIEL- UND/ODER UNTERHALTUNGSGERAT ECLI:EP:BA:2016. 
of any distinctive character. ${ }^{54} \mathrm{~A}$ mark devoid of any distinctive character is considered, in particular, as one which does not enable the relevant public 'to repeat the experience of a purchase, if it proves to be positive, or to avoid it, if it proves to be negative, on the occasion of a subsequent acquisition of the goods or services concerned' ${ }^{55}$ It appears that in order to be successfully registered, an element of a GUI needs to be unusual, striking and memorable in relation to the goods in question, standing out from other marks in the same sector; under such circumstances, it may be viewed by the average consumer as indicating origin.

For example, in one instance the subject matter of Microsoft Corporation's application consisted of 'representation of two transparent regions in the shape of a bar having a curved end' along the upper and lower right position of the computer screen. ${ }^{56}$ The Board found that this did not represent a characteristic notably different from those commonly found in similar products. According to the Board, in the software sector, in which consumers are used to seeing a wide variety of designs, it would be unlikely that the average consumer would be able to perceive a mere variation in the design of the upper and lower bar on a computer screen as an indication of the software's commercial origin. Hence, the Board concluded that the mark applied for was not capable of leaving a lasting impression on the target public as an indication of commercial origin.

In the same vein and on a similar basis, the Board of Appeal refused another application of Microsoft, this time relating to the overall layout of a GUI. ${ }^{57}$ The mark applied for consisted of two columns of rectangular tiles, with certain text and images applied to these tiles. The Board found that most mobile devices represent rectangular icons symbolising their content on the screen. The arrangement of these rectangles was a purely functional feature on the device and its operating system, and was not perceived as an indication of origin by an average consumer.

Twitter's application for a GUI-based device mark, comprising four images (left arrow, two mutually chasing arrows, five pointed star and ellipsis) was similarly refused as being devoid of any distinctive character. The EU IPO maintained that the sequence of images did not possess any aspect that would render it memorable. The Board was not convinced by the appellant's argument, according to which there was a certain degree of originality in the symbols contained in the sign. It held that the graphical representation of the symbols was not of such a nature as to hold the consumers' attention. Furthermore, according to the Board, consumers were likely to perceive the graphical stylisation as a mere carrier of the symbols and not mentally register the moderate figurativeness as an element imparting a sufficiently high degree of distinctiveness on them.

Apple's application for registering its well-known 'Contacts' icon, consisting of a personal organiser in the form of an address book where the content can be displayed in alphabetically ordered folders, did not fare better and was found to be devoid of any distinctive character, inter alia, in relation to mobile devices, even though it has been accepted as being inherently distinctive in a number of countries including Australia, New Zealand, the US, Canada, China and Japan. ${ }^{58}$ In reaching its decision the Board referred to examples of similar icons available

54 Directive (EU) 2015/2436 of the European Parliament and of the Council of 16 December 2015 to approximate the laws of the Member States relating to trade marks (Trade Marks Directive), art 4(1)(b).

55 See Case T-79/00 EWE-Zentral v OHIM (LITE) ECLI:EU:T:2002:42, para 26.

56 Decision of the 2nd Board of Appeal of 11 April 2006, Case R 64/2006-2.

57 Decision of the 5th Board of Appeal of 7 November 2014, Case R 253/2014-5.

58 Decision of the 5th Board of Appeal of 25 January 2016, Case R 1616/2015-5. 
on the market, and concluded that the overall impression of each one of these symbols was that of an icon for storing contact information and the like, and not of a fanciful trade mark. The Board held that in the same vein, the average consumer would not prima facie perceive the mark applied for as an indicator of trade origin but simply as a software application icon with a specific purpose (storing and managing one's contacts). The applicant's arguments regarding acquired distinctiveness were also rejected. ${ }^{59}$ The Board stressed that although there was no doubt that the applicant has been hugely successful with its products such as the iPhone and iPad and that many millions of people have been exposed to the mark applied for both in Europe and worldwide, the evidence provided did not contain any information as how the average consumer perceives the mark applied for in isolation. It is difficult to envisage the type of evidence that would have sufficed in this context, as Apple is not likely to rely on the mark applied for 'in isolation' as an indication of origin. ${ }^{60}$

It appears that the Boards may be applying the acquired distinctiveness criteria in a particularly stringent manner when related to GUI components. While it is correct that Apple never used the mark applied for in isolation, it should be sufficient to show for the purpose of acquired distinctiveness that the relevant public recognises the mark as originating from Apple. For example, in Nestle the CJEU was asked by the referring court: 'May the distinctive character of a mark referred to in Article 3(3) of [the Directive] and Article 7(3) of [the regulation] be acquired following or in consequence of the use of that mark as part of or in conjunction with another mark?'61 The Court's response was clear:

such identification, and thus acquisition of distinctive character, may be as a result both of the use, as part of a registered trade mark, of a component thereof and of the use of a separate mark in conjunction with a registered trade mark. In both cases it is sufficient that, in consequence of such use, the relevant class of persons actually perceive the product or service, designated exclusively by the mark applied for, as originating from a given undertaking. ${ }^{2}$

Hence, the CJEU in Nestle made it clear that the fact that a mark is not used independently by an applicant was of little consequence when deciding on acquired distinctiveness. What was of importance was the relevant public's recognition of the mark applied for as originating from a specific undertaking. The same rationale was subsequently applied by the CJEU in Colloseum, ${ }^{63}$ in relation to the definition of genuine use. ${ }^{64}$ Applying this rationale to the Apple

59 CTMR, art 7(3); according to the CJEU, when deciding on whether a mark has become distinctive through use, account must be taken of factors such as, inter alia: the market share held by the mark; how intensive, geographically widespread and longstanding use of the mark has been; the amount invested by the undertaking in promoting the mark; the proportion of the relevant class of persons who, because of the mark, identify goods as originating from a particular undertaking; and statements from chambers of commerce and industry or other trade and professional associations. If, on the basis of those factors, the relevant class of persons, or at least a significant proportion thereof, identify goods as originating from a particular undertaking because of the trade mark (see Joined Cases C-108/97 and C-109/97 Windsurfing Chiemsee Productions v Boots [2000] Ch 523; Case C-299/99 Philips v Remington [2003] RPC 2; Case T-396/02 Storck v OHIM ECLI:EU:T:2004:329; Case C-24/05P Storck v OHIM ECLI:EU: $\mathrm{C}: 2006: 421)$.

60 Consumer surveys may be the only option in that respect.

61 Case C-353/03 Société des produits Nestlé SA v Mars UK Ltd [2005] ECR I-6135, para 17.

62 ibid para 30.

63 C-12/12 Colloseum Holding AG v Levi Strauss \& Co EU:C:2013:253 [2013] ETMR 34.

64 Under the then applicable Article 9(1)(b) of Regulation No 40/94. 
context, it appears that Apple may have adduced sufficient evidence to establish such public recognition. The Board's restrictive application of the acquired distinctiveness criteria in this case may hint to its overall lack of enthusiasm regarding registrability of GUIs or components thereof. There may be sound policy considerations against registration of marks that were only ever used in conjunction with other registered marks, where the applicant would never dream of using such marks in isolation as a designation of origin. However, as long the Nestle approach prevails, it makes little sense to mark out GUIs or components thereof and have them facing a tougher registrability hurdle in relation to establishing acquired distinctiveness.

The examples discussed above should not lead one to conclude that GUIs or elements thereof do not stand a viable chance of being registered. Ultimately, each instance depends on its own individual facts, and where the EU IPO is convinced that there is sufficient degree of inherent or acquired distinctiveness, the application may be accepted. ${ }^{65}$

\subsection{Shapes or Other Characteristics Which Are Necessary to Obtain a Technical Result, or Give Substantial Value to the Goods}

Until recently, the exclusions from registration under Article 4(e) of the Trade Marks Directive applied to three dimensional shapes only and therefore were not likely to be applicable to the elements in GUIs. It was only in the revised version of the Trade Marks Directive that passed on 16 December 2015 that the said limitation was removed, and Article 4(1)(e) now refers to 'the shape, or another characteristic of goods'. It is thus clear that the revised version of Article 4(e) is potentially applicable both to two and three dimensional features of a product.

Article 4(1)(e)(ii) provides that signs which consist exclusively of the shape, or another characteristic, of goods which is necessary to obtain a technical result shall not be registered. Although the above provision is new and there is no decision on its scope at present, there is ample guidance from the CJEU on what constitutes 'necessary to obtain a technical result' in relation to three dimensional shapes. Subject to the necessary changes, these principles could equally apply to 'another characteristic of the goods', including two dimensional features in GUIs.

In Philips $v$ Remington, ${ }^{66}$ the CJEU concluded that where the essential characteristics of the shape of a product are attributable solely to a technical objective, registration is precluded even if other shapes can achieve the same technical result. Subsequently, the CJEU in Lego elaborated on the manner in which such assessment should be carried out and maintained that the expression 'essential characteristics' must be understood as referring to the most important elements of the sign. ${ }^{67}$ Once the essential characteristics have been identified, the court should decide whether such characteristics perform the technical function of the product concerned; alternative configurations achieving the same function equally well are of little relevance. It is the objective and function of those essential characteristics that is decisive. The identification of those essential characteristics must be carried out on a case by case basis. Supporting evidence such as patents or statements by the designer will be given considerable weight in

65 For example, Apple has several figurative EUTM registrations for GUIs; inter alia, it registered individual application icons as well as the homepage layouts of the iPad $(009265588$, registered on $19 / 04 / 2011$ in classes 9, 16, 18, 28, 35, 37, 38, 41, 42), as well as the homepage layout for the Apple Watch (013728555), registered 14/09/2015 in classes 9, 10, 14, 28).

66 Case C-299/99 Philips v Remington [2003] RPC 2.

67 Case C-48/09 P Lego Juris A/S v OHIM, Mega Brands Inc [2010] ETMR 63, para 69. 
uncovering such objective. It should be noted that the assessment under Article 4(e) should be carried out independently of the distinctiveness enquiry discussed above. Hence, even where the shape or other characteristic is perceived by the public as emanating from a specific trade origin, registration should still be refused where it is found that its essential characteristics are attributable to obtaining a technical result. In such circumstances, a third party that appropriates such characteristics may be enjoined under domestic unfair competition; EU trade mark law, however, will not be engaged.

It is noteworthy that the CJEU did not endorse the alternative shapes or characteristics approach. Unlike the eligibility filter for copyright law, where alternative forms of expression were held to indicate subject matter that was not dictated by functionality, the CJEU broadened the scope of the exception in the case of trade marks so that even where alternatives achieving the same function were available, a subject matter could still be precluded from registration on a functionality basis where its essential characteristics were attributable to obtaining a technical result.

Although it is correct to describe many GUI features as functional in the sense of being designed to achieve a utilitarian objective, they are not likely to fall foul of Article 4(e)(ii). The reason is that the function of such features will rarely be attributable to the relevant text or image in relation to which registration is sought. Hence, the essential characteristics are not likely to be classified as 'necessary' in order to achieve the technical result that the said feature aims to facilitate. For example, let us take Apple's 'Contacts' icon mentioned above, in respect of which Apple failed to establish a sufficient level of distinctive character. Leaving aside the question of distinctiveness, is it likely to contravene Article 4(e)(ii)? After identifying the essential characteristics, most of which relate to the manner in which the human silhouette and the address book images are depicted therein, a court would turn to determining whether these are necessary to obtain a technical result. The answer to such query should be negative. While some elements of GUIs may be essential for obtaining a technical objective, such as Apple's 'pinch to zoom' or 'genie dock' functions, they are not likely to be the subject of a trade mark application and, if at all, may rather be the subject of a patent application. It is submitted that the majority of such features are likely to easily clear the hurdle of Article 4(e)(ii).

The closest EU equivalent to the US aesthetic functionality doctrine is found in Article 4(1)(e)(iii). In its present version this provision states that a sign that consists exclusively of the shape or another characteristic which gives substantial value to the goods is precluded from registration. This provision is aimed at precluding the registration of signs consisting of features that have substantial aesthetic appeal. Some GUI elements, such as icons or animated features, are clearly aesthetic and may have considerable eye appeal. Where that is the case, are such elements likely to fall foul of Article 4(e)(iii)?

Bang \& Olufsen provides some guidance as to the manner in which the assessment under this provision is to be carried out. ${ }^{68}$ In this case the General Court of the European Union (EGC) found that the design of hi-fi speakers, the shape of which Bang \& Olufsen sought to register as a trade mark, was very important for consumers' choice, even though consumers may have taken other characteristics of the goods at issue into account as well when making their purchasing decision. It was also shown that the design was an essential element of Bang \& Olufsen's branding, increasing the speaker's appeal and, hence, its value to consumers.

68 Case T-508/08 Bang \& Olufsen A/S v OHIM [2011] ECR II-6975. 
Distributors' promotional literature emphasised the aesthetic characteristics of the shape, which was perceived according to the EGC as a kind of pure, slender, timeless sculpture for music reproduction, thus constituting an important selling point. Relying on the evidence described above, the EGC concluded that the speakers' shape added substantial value and was therefore barred from registration as a trade mark.

As in the case of Article 4(e)(ii), it is unlikely that most GUI-based marks will contravene Article 4(e)(iii). Is a highly aesthetic icon or animated feature, for example, likely to add substantial value to a mobile device within the meaning of the EGC's analysis in Bang \& Olufsen? What about the overall layout of a GUI? It is submitted that in both instances the answer is likely to be negative. Although intuitive and visually appealing GUIs are overall important to the success of a GUI-based product, signs consisting of features thereof, evaluated individually under Article 4(e)(iii), are unlikely to be found to add substantial value to the device in which they are embedded. As regards the overall screen layout, while its intuitiveness could indeed add considerably to the value of a GUI-controlled device, it is the user-friendliness of such a GUI that is likely to do so rather than its aestheticism.

Finally, it should be noted that the exclusions under Articles 4(e) (ii) and (iii) apply to shapes and other characteristics of 'goods'. Hence, where the registration of signs consisting of GUI features is sought in respect of services, as may be the case in relation to a software-based service provided over a network, Articles 4(e) (ii) and (iii) are not engaged regardless of any technical result achieved or substantial value added as a result of using the mark applied for.

\subsection{Summation}

We have seen that the most formidable hurdle for registering elements of GUIs as trade marks is the one facing applicants in general when attempting to register elements of their product's trade dress: the requirement of distinctiveness. The CJEU case law suggests that only in the minority of cases trade dress would be found to be inherently distinctive.$^{69}$ Boards of Appeal decisions on registrability of GUIs suggest the same. Strangely, it also appears that when establishing acquired distinctiveness, widespread exposure of the public to the GUI at issue and significant commercial success of the product in which it is embedded would not suffice, as the Boards may require to see evidence on how the public perceives the mark applied for in isolation. This may be difficult to establish where the GUI component at issue is always used in conjunction with other registered trade marks, as the case may often be.

However, where a GUI or elements thereof are found to possess some distinctive character, whether inherent or acquired, it appears that the absolute grounds for refusal criteria should not necessarily prove more challenging in the case of GUIs than in the more general case.

69 On three dimensional shapes, see Case C-24/05 P Storck v OHIM ECLI:EU:C:2006:421, para 24 (stating 'Average consumers are not in the habit of making assumptions about the origin of products on the basis of their shape... only a mark which departs significantly from the norm or customs of the sector $\ldots$ is not devoid of any distinctive character'). 


\section{GUIS AND INDUSTRIAL DESIGN RIGHTS}

The EU offers two parallel systems for protection of industrial designs: registered and unregistered design regimes. ${ }^{70}$ The substantive eligibility requirements relating to the merits of the designs at stake are essentially the same; there are nevertheless significant differences between the two regimes pertaining to issues such as scope of protection, term of protection, disclosure requirements and more. ${ }^{71}$

A software proprietor could either seek to protect his GUI or elements thereof before he commercialises it, and obtain a registered community design (RCD), or he could proceed to commercialise it directly and rely on an unregistered community design right (UCD), as long as such design was first made available to the public in the EU. Since its scope of protection is significantly stronger and its term of protection is significantly longer, there is clear benefit in having a GUI or part thereof registered with the EUIPO.$^{72}$ It should be noted that once a GUI, icon or feature thereof relating to one product, such as a smartphone, is registered, it is also protected against use by a third party in another product such as the display on a smart TV. In this sense, the RCD regime is clearly advantageous compared with trade marks. The discussion below will focus on the EU RCD regime.

\subsection{Eligibility}

An application for RCD in relation to icons and GUI should ideally refer to Class 14, Sub-class 04 of the Lucarno Classification. ${ }^{73}$ A brief examination of the EUIPO database shows that there are multiple RCD registrations for GUIs or elements thereof. ${ }^{74}$ Although there is no substantive 'ex ante' examination of RCD applications as there is in the case of trade marks, it is nevertheless indicative of the readiness of the EU RCD regime to accommodate subject matters consisting of GUIs or elements thereof. In fact, the EU is not unique in this respect,

70 Henceforth the discussion below refers to Council Regulation (EC) No 6/2002 of 12 December 2001 on Community designs (consolidated version) (hereinafter CDR).

71 'Designs in the European Union' (European Union Intellectual Property Office) $<$ https://euipo .europa.eu/ohimportal/en/designs-in-the-european-union> accessed 23 October 2019.

${ }^{72}$ For example, while UCD protects against copying, RCD protects against use, whether or not resulting from copyright; while the UCD term of protection is three years, RCD can potentially last for 25 years.

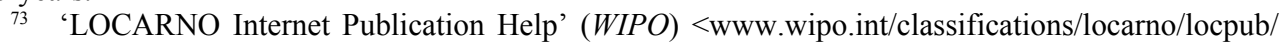
en/fr/help/> accessed 23 October 2019; Class 14: Recording, communication, or information retrieval equipment; Subclass 04: Screen Displays and icons. Computer screen displays, graphic interfaces, interfaces for display screen, screen displays, screen graphics, graphical interfaces, graphic representations for user interfaces, user interfaces.

74 For illustrative examples representing various types of GUI features registrations, see the following registered designs: 004418630-0001; 004422152-0001; 001062939-0001; 001062939-0002; 004139491-0001 to 004139491-0006; 004411379-0001 to 004411379-0002; 003556257-0001; 002664771-0003; 001228480-0001 to 001228480-0003; 003407527-0005 and 003407527-0007; $002153080-0020$ and $002153080-0021$; 001359830-0001 to 001359830-0004; 002601435-0001; 002705848-0006; 000600184-0008; 001100598-0009; 000754098-0001. 
as most jurisdictions worldwide offer industrial design or design patent protection in such instances. $^{75}$

The definition of a design eligible for registration under the CDR is fairly broad: 'the appearance of whole or part of product resulting from features of, in particular, the lines, contours, colours, shape, texture and/or materials of the product and/or its ornamentation. ${ }^{76}$ A product is defined as: 'any industrial or handicraft item including parts to be assembled into complex product, packaging, get-up, graphic symbols, ${ }^{77}$ and typographical typefaces, but excluding computer programs' ${ }^{78}$ Although computer programs are explicitly excluded from protection, GUIs, webpage designs and icons may constitute a 'product' and could therefore be protected as an industrial design. ${ }^{79}$ In this context it should also be noted that a GUI or feature thereof can be registered independently from the product that incorporates it.

In order to be protected as a RCD, a design must be novel and have an individual character. ${ }^{80}$ Essentially, these substantive requirements do not pose an additional difficulty in the context of GUIs and therefore do not merit special consideration in the present context. In order to satisfy the novelty requirement, it must be shown that an identical design has not been made available to the public prior to the priority date ${ }^{81}$ The individual character requirement will be satisfied where the overall impression it produces on the informed user differs from the overall impression of an earlier design made available to the public. ${ }^{82}$

As in the case of trade mark law, the RCD regime also includes an exclusion relating to technical function. Article 8(1) CDR provides: 'A Community design shall not subsist in features of appearance of a product which are solely dictated by its technical function'. Recital 10 explains: 'Technological innovation should not be hampered by granting design protection to features dictated solely by a technical function. It is understood that this does not entail that a design must have an aesthetic quality.' The rationale for this exclusion is also similar to that underlying the functionality exclusion in trade mark law: features that are solely dictated by a technical function should be evaluated and, where suitable, protected under patent law rather than the laxer standards of RCD; otherwise, such protection may have considerable anticompetitive repercussions. ${ }^{83}$

75 See countries' Replies to the Questionnaire on Industrial Design Protection for GUIs, Icon and Typeface/Type Font Designs: 'Standing Committee on the Law of Trademarks, Industrial Designs and Geographical Indications' (WIPO) < www.wipo.int/edocs/mdocs/geoind/en/sct_36/sct_36_2_rev_2 .pdf> accessed 23 October 2019.

$76 \mathrm{CDR}$, art 3(a).

77 The protectability of typeface is relevant in the GUI context, since a particular type of typeface may constitute part of the look and feel of a GUI; for example, see RCD 000130299-0001.

78 CDR, art 3(b).

79 See David Stone, European Union Design Law: A Practitioner's Guide (OUP 2012), para 4.76; for example, see RCD 930367-0002 registered for an icon for a portion of a display screen.

80 CDR, art 4(a).

81 CDR, art 5.

82 CDR, art 6.

83 Uma Suthersanen, Design Law: European Union and United States (2nd edn, Sweet \& Maxwell 2010) 101 . 


\subsubsection{Features dictated solely by technical function}

Until recently, there was no uniformity across the EU in relation to the manner in which a court is to determine whether a design feature is 'dictated solely by a technical function' under Article 8(1) CDR. Two main tests have been used for this purpose.

According to the 'multiplicity of forms' test, the exception under Article 8(1) is engaged only if the technical function at issue cannot be achieved by any other configuration; if the designer has a choice between two or more configurations, the appearance of the product is not solely dictated by its technical function. One of the main criticisms made in relation to this approach is that where only a limited number of configurations are possible, an applicant might gain a monopoly over a function by registering them all, effectively foreclosing the use of the technical function at issue to all competitors.

The 'multiplicity of forms' approach is fairly lax when it comes to engaging Article 8(1). It is sufficient for one alternative configuration achieving the same function to be identified for the technical function exclusion not to apply. In the case of GUIs, it is difficult to conceive scenarios where there would be no alternatives to a given design or configuration. If this was to prove the prevailing approach to the application of Article 8(1), it would follow that the technical function exception would hardly make any difference in the case of GUIs and that occasions where GUI features would be caught by the technical function exclusion would be extremely rare. This test has been endorsed in some early EUIPO decisions, by some national courts - including the German, French, Spanish, and Swedish ones - and by the Advocate General in the trade mark case Philips $v$ Remington. ${ }^{84}$ However, the 'multiplicity of forms' approach has been recently rejected by the CJEU. ${ }^{85}$ In Doceram the CJEU first determined that the availability of alternative designs is of little relevance to the application of Article $8(1)$. According to the court, the latter provision

excludes from the protection conferred ... a case in which the need to fulfil a technical function of the product concerned is the only factor determining the choice by the designer of a feature of appearance of that product, while considerations of another nature, in particular those related to its visual aspect, have not played a role in the choice of that feature. ${ }^{86}$

Moving on to consider the method for assessing the conditions of Article 8(1), the CJEU stipulated that all the objective circumstances of the case must be taken into account by the court in making the said assessment under Article 8(1). Importantly, such assessment does not require that the perception of the 'objective observer' should be taken into account. The court stated that:

such an assessment must be made, in particular, having regard to the design at issue, the objective circumstances indicative of the reasons which dictated the choice of features of appearance of the product concerned, or information on its use or the existence of alternative designs which fulfil the same technical function, provided that those circumstances, data, or information as to the existence of alternative designs are supported by reliable evidence. ${ }^{87}$

84 Stone (n 79) para 6.11.

85 Case C-395/16 Doceram v CeramTec EU:C:2018:172, [2018] ECDR 13.

86 ibid para 26.

87 ibid para 37. 


\section{Research handbook on intellectual property and digital technologies}

Hence, by reference to objective circumstances, rather than attempting to determine the subjective state of mind of the designer, a court should establish whether there was any factor other than technical function, such as aesthetic appeal, leading to the choices made by the designer. Where that is not the case, the design at issue contravenes Article 8(1).

\subsection{Summation}

In the context of GUIs, the Doceram approach is likely to lead to the exclusion under Article 8 (1) being triggered more often than in the case of the 'multiplicity of forms' approach. For example, an innovative design feature of a GUI that is motivated by efficiency of use considerations with a view to rendering the interaction between user and device more intuitive may contravene Article 8(1), unless other considerations leading to the design choices made could be objectively identified. In comparison, under the multiplicity of forms approach such design or configuration could be compatible with Article 8(1) as long as there is at least one more design alternative capable of achieving the same technical objective, which in the case of GUI is almost always likely to be the case. Interestingly, we have seen that in the case of GUIs, designs that have the effect of 'lowering the cognitive burden' of the user, although of great value, are not likely to be patentable under the present jurisprudence at the EPO as they are not considered to have a technical effect. However, this 'lowering of cognitive burden' and the efficiency considerations related to it may prove sufficient to render a given design 'technical' and hence be excluded under Article 8(1) for RCD purposes. This may lead to a situation where innovative designs that enhance the intuitiveness of GUI-controlled devices or services are left unrewarded under our IP regime; such designs may be considered as lacking in technicality under our patent regime and therefore unpatentable, while at the same time being considered as dictated solely by a technical function under our RCD regime and hence excluded from protection under Article 8(1).

\section{CONCLUSIONS}

We have seen that GUIs or features thereof that are authentically pleasing may be protected under copyright law, the EU industrial designs regime and, possibly, trade marks law. ${ }^{88}$ Similarly, GUIs or features thereof that are sufficiently unique and recognisable may be protected under trade marks law, as long as they are not devoid of distinctive character. Essentially, as in the context of trade dress in general, that means that acquired distinctiveness will almost always need to be established.

However, it appears that one of the most sought after types of GUI is falling between two stools when it comes to IP protection. As mentioned at the beginning of this chapter, GUIs that speed and simplify the operation of and interaction with GUI-controlled products or services, enhancing the efficiency of such interaction between user and software, have a considerable impact on the commercial success of the device or service at issue and are therefore highly desirable. Notwithstanding, protection of such GUIs or features thereof under the EU's IP framework is somewhat lacking. While admittedly such designs or configurations might

88 Regarding trade mark law, such aesthetic appeal must not add substantial value to the goods. 
be protected under copyright law in relation to the exact form of expression chosen by the developer, as the functionality of such design does not render it ineligible under copyright law as long as alternative forms of expression may achieve the same objective, such protection may prove rather 'thin' and may fail to protect against appropriation of the efficiency enhancing element of such innovative designs. Turning to EU's industrial designs and trade mark regimes, such efficiency enhancing properties, which mark out the said designs from the 'state of the art', might actually render the said GUIs ineligible for protection as they may contravene the functionality exclusion under both regimes. At this point an observer may comment that such a state of affairs is desirable and that efficiency enhancing properties resulting in more intuitive and speedy operation of technical devices should be protectable under patent law. However, we have seen that this is not the case under the present jurisprudence of the EPO, where the 'lowering of cognitive burden', resulting in more efficient and speedy interaction between user and GUI-controlled product or service, does not constitute a 'per se' technical effect unless some objectively verifiable physiological effect could be demonstrated.

In light of the above, and in order to improve the likelihood that successful intuitive and efficiency enhancing designs will gain protection as either trade marks, or, even more so, registered designs, it is advisable that any GUI development process may not be guided solely by functional considerations and that other considerations, such as aesthetic appeal, also play a role in that process. Where that is the case, such designs are not likely to fall foul of the functionality exclusion under both aforementioned regimes. Keeping a paper trail of the design process which demonstrates that indeed considerations other than functional ones played a role in the design process may prove vital in gaining such protection. 